\title{
SHAPE: A Healthy Aging Community Project Designed Based on the Salutogenic Theory
}

\author{
Betsy Seah and Wenru Wang
}

\section{Abstract}

Salutogenesis introduces a paradigm that requires a perceptual change towards what creates health and how health can be facilitated. Removing the lens of pathogenesis, aging is an achievement to be embraced and older people are valued as assets for their wealth of experiences, resources, skills and knowledge. From the perspectives of older adults, the concept of healthy aging is multidimensional, comprising bio-psycho-socialspiritual health. Evidence shows that sense of coherence via resistance resources promotes health outcomes among older adults. However, very few works have attempted to operationalise the salutogenic theory to promote healthy aging among older community dwellers. This chapter provides a detailed description of the Salutogenic Healthy Aging Program Embracement (SHAPE) intervention for senior-only household dwellers. SHAPE represents an application of the salutogenic concepts: sense of coherence and resistance resources. SHAPE is an integrative personcentric multi-dimensional health resource program that employs an asset-based insight-

B. Seah $(\bowtie) \cdot$ W. Wang

Alice Lee Centre for Nursing Studies, Yong Loo Lin

School of Medicine, National University of

Singapore, Singapore, Singapore

e-mail: nurseah@nus.edu.sg; nurww@nus.edu.sg oriented approach. Illustration of examples in which how the salutogenic concepts were operationalised in developing the SHAPE intervention approach, its content, activities and the conduction of the intervention are presented.

\section{Keywords}

Salutogenic health theory $\cdot$ Sense of coherence Resistance resources $\cdot$ Healthy aging $\cdot$ Older adults $\cdot$ Community-based care $\cdot$ Asset-based approach $\cdot$ Health promotion

\subsection{Introduction}

Normal aging is a precursor of pathology and influence the degree of disease presentation, response to treatment and probability of developing complications [1]. It sets the challenge of approaching aging from the salutogenic perspective in identifying factors that create health among older adults. With aging as a disease and frailty risk factor [2-4], efforts to promote health in older people commonly focus on disease prevention, reducing frailty and disability. In a scoping review performed on past systematic reviews of interventions targeting health maintenance or improvement of older adults, majority of them focused on disease-specific interventions [5]. 
Removing the lens of pathogenesis, aging is an achievement to be embraced; where older people are valued as assets for their wealth of experiences, resources, skills and knowledge. Advocated in the 2002 Madrid International Plan of Action on Aging, older adults should be continued to be developed, supported by the environment and to live with health [6]. However, there are very few works that attempted to operationalise the salutogenic theory in cultivating such environments by developing interventions for older adults to age healthily. This book chapter documents the development of a health resource program, titled Salutogenic Healthy Aging Program Embracement (SHAPE), for older community dwellers residing in senior-only households using the salutogenic theory.

\subsection{Healthy Aging as a Multidimensional Concept}

Having an understanding towards older community dwellers' perceptions towards contributing factors of healthy aging allows health professionals to strategize and align health promotion interventions effectively to facilitate this pursuit. A literature search was performed to identify qualitative studies which explored views of healthy aging among independent older community dwellers. Unlike quantitative studies, qualitative evidence synthesis provides an in-depth and nuanced understanding towards the concept of healthy aging across different contexts. The included studies were conducted in Canada [7, 8], Germany [9], Hong Kong [10], Hungary [9], Latvia [9], Malaysia [11], Netherlands [12], New Zealand [13], Sweden [9], Thailand [14, 15], the United Kingdom [9] and the United States [1619]. The following in Sect. 23.2 presents the synthesized findings of these 13 qualitative studies.

\subsubsection{Having Physical and Mental Health}

Some older adults referred physical well-being as absence of chronic diseases [10, 15] while oth- ers acknowledged illness as part of late life [13, 17]. Having physical health meant not suffering from complications or debilitating conditions which impair daily activities [14, 17]. Abilities deriving from physical health allow one to fulfil one's spiritual desires [11], everyday activities [12] and meaningful activities [16]. Having a balanced state of mind was important too as older adults recognized that mental health was connected to physical health [17]. Having good cognitive function was also recognized in five studies and some older adults reported the importance of engaging in cognitive stimulating activities to avoid or delay decline $[7,9,11,14,17]$.

\subsubsection{Positive and Optimistic Outlook}

Older adults in five studies reported that having positive and optimistic outlook was an essential element to healthy aging. Maintaining positivity and optimism towards changes in own health and aging experiences influenced how one coped and adapted to these challenges [12], such as through acceptance of situation [7, 17], hope [17], reframing of situation [17], and instilling a sense of self, self-confidence and self-efficacy in knowing what to do with the situation [16]. Having a positive and optimistic outlook gave the older adults a sense of control and willpower over health and own lives [7, 12, 15, 16]. In Thailand, having positive psycho-emotional outlook contributes to one's internal state of mind and it is related to Buddhism [15]. Healthy older adults were perceived to be friendly, humorous and enjoyable too [15].

\subsubsection{Being Socially Connected and Supported}

Another aspect of healthy aging is social health. A supportive social environment consisted of family members, partner/spouse, friends, neighbours, acquaintances and the presence of social activities [12]. Often, valued relationships involved reciprocity, contact, engagement, caring 
and companionship [7, 13, 15, 16]. Participation in social activities was reported important as this mitigated feeling of isolation, loneliness abandonment, fostered relationships and promoted sense of fulfilment [17]. Social activities could be related to their social roles [16] and social contributions $[13,15]$. Older Malay adults contributed to their families as responsibility towards children and grandchildren was perceived as a lifelong commitment [11]. However, immobility due to pain and disability [7, 16], financial constraints, lack of transport [13], cultural and linguistic background among minorities [17] were reported to limit social opportunities.

\subsubsection{Being Spiritual and Religious}

Seven studies mentioned that being spiritual and religious contributed to healthy aging. The doctrine of faith offered older adults positive outlook and acceptance towards difficult agingrelated encounters $[16,17]$ and a peace of mind to balance feelings and material desires $[11,14$, 15]. Having spiritual and/or religious beliefs freed older adults from worries and anxiety over uncontrolled future, placing their health and late life in the hands of the higher being $[14,17,18]$ and preparing them for the end of life and acceptance to death [11, 14]. Being spiritual included having a peaceful life [11, 14], doing good, being a role model and being useful $[11,14,15]$. Having to receive positive feedback from people gave them happiness, pride, meaning in life and higher self-esteem [14]. Moreover, being spiritual and religious was perceived to be associated with healthy lifestyle among African Americans [18]. Spiritual-religious activities involved praying, offering services, donating and going to churches, mosques and temples [11, 15, 19].

\subsubsection{Being Active and Committed to Healthy Behaviours}

Another key component of healthy aging was to stay active physically, mentally and socially in their daily lives $[7,9,17,19]$. To engage in activi- ties which were pleasurable [13], fun [15], meaningful and worthwhile to do was important $[7,13$, 16]. These activities varied from physical exercises, volunteering, gardening, puzzles, reading, watching television, lottery and other leisure pursuits $[13,16]$. With increased awareness towards ailing health, some reported having difficulties in staying active and had to negotiate competing priorities to continue their pursuit of valued activities [9, 13]. Older adults also identified the importance of committing to healthy behaviours by having self-discipline and making conscious choices to take charge of own health [9, 17]. These behaviours included having balanced and healthy diet, exercising, having enough sleep, not smoking, not drinking, taking medicine as prescribed, attending regular medical check-ups and adhering to doctor's advice [15, 17]. Although taking self-initiative was important [7], some older adults reported the lack of motivation to maintain healthy lifestyle behaviours [19].

\subsubsection{Being Independent}

Having to maintain and preserve independence was a key contributor to healthy aging in almost all studies. Being independent was a sense of pride and an existential identity in one's home [9, 16]. It meant that the older adults can make their own decisions [7, 13, 14], take care of themselves [13-16, 18], get around on their own [7, 13, 16], and be self-sufficient [7, 9, 17]. Few studies reported their fear of losing independence $[7,16$, 17] as it would erode their self-worth and dignity [17]. The studies showed that independence was also a cultural value. Older adults from cultures with strong familism such as Hong Kong, Thailand and Ethiopia, reported having interdependence with family $[10,14,19]$ and health care professionals [14] were part of healthy aging.

\subsubsection{Being Safe and Secure}

Feeling safe and secure, in terms of finances and living environment, played a role in healthy aging as reported in nine studies. This became 
apparent among older adults who struggled with financial independence to make ends meet and had no substantial savings for late life, bringing them stress, insecurity and uncertainties [13, 17]. Older adults in Latvia and Hungary expressed their fear of becoming homeless while those from Sweden, Germany and United Kingdom reported barriers in accessing or unawareness of financial help for home improvement works [9]. Financial constraints also have consequential effects on health behaviour practices such as limited food choice while on budget [13]. For older adults from Hong Kong and Malaysia, being in a financial state which support a reasonable lifestyle and material needs mattered and would suffice $[10,11]$.

Being in a living environment that gave older adults daily sense of security and safety was crucial too. It included the house lived in, the people they live with in the neighbourhood and the amenities around [11]. Having physical comfort of a home, which is a basic need, gave older adults warmth [13]. Particularly, older adults whom were formerly homeless reflected that having a home protected them from bad weather, contagious diseases and unsafe physical environment, and brought about access to nutritious food, social support, income support, better hygiene and self-care [8]. With increasing frailty, some older adults felt less safe at home [13]. Others expressed concerns of burglars and unknown neighbours [13]. One study reported that healthy behaviours such as walking as an exercise was limited as African Americans older adults felt unsafe in their neighbourhoods [18]. Moreover, proximity and familiarity towards social support and environmental amenities provided older adults with access and increased their sense of control towards utility of nearby resources [12].

Based on the above literature, older adults' perspectives towards healthy aging spread across multiple aspects of later life, including biopsycho-social-spiritual health. The above review also suggested that healthy aging interventions need to be cultural-sensitive and explore contextual factors unique to the targeted older population's characteristics.

\subsection{The Salutogenic Theory}

\subsubsection{The Salutogenic Orientation}

In the salutogenic health theory, Antonovsky compared salutogenesis and pathogenesis. According to the traditional biomedical approach, homeostasis is the regulation of human life and any occurrence of disease or risk factor disrupts the homeostatic human living environment. The homostasis model focuses on pathogenesis, searching for factors that cause diseases and reduce risk factors [20]. This contrasted with the salutogenesis. It took on the assumption of heterostasis where we live in an environment full of turbulence, stress and instability.

Antonovsky proposed that each of us is on different positions of the health ease/dis-ease continuum, with total health (ease) and total ill health (disease) at the two poles of the continuum. However, this position on the continuum is not static. In the presence of a stressor which creates tension in an individual, one's ability to cope successfully results in salutogenesis, and a movement towards the total health of continuum. Contrarily, failure to cope results in pathogenesis, the movement towards total ill health [20]. Thus, in the salutogenic perspective, health is a process and its scope is non-limiting, multi-faceted and subjective [21].

Antonovsky argued that the focus on diagnoses in the traditional biomedical approach discounted the 'story of the person' (p. 5) or the perspective and context of an individual [20]. This limits the optimisation of one's health potential. While outcomes of pathogenesis are confined to eliminating diseases and minimising deficits, the end-goal of salutogenesis is active adaptation to problems encountered in a stressor-rich environment. The latter provides the possibility of being healthy despite hardship, misfortune and illness. Nonetheless, health care professionals should not boycott the traditional biomedical approach, as managing diseases and risk factors are important. Both salutogenic and pathogenic approaches are complementary and should be embraced and practiced with equal importance [20, 22].

Central to the salutogenic theory are the following concepts of sense of coherence (SOC), and generalised and specific resistance resources. 


\subsubsection{Sense of Coherence}

SOC is both a life orientation and a resource. This global perceptual influence affects how one copes cognitively, behaviourally and emotionally with tension caused by stressors [21]. It comprises the following three components: comprehensibility, manageability and meaningfulness.

Comprehensibility refers to how well one perceives the character and phenomenon of the stressor as consistent, expected and clear; Manageability refers to one's capacity to mobilise existing resources at one's disposal to cope with the stressor; and Meaningfulness refers to one's appraisal of the value and experience brought about by the stressor [20]. Thus, an individual with a strong SOC perceives life as comprehensible, manageable and meaningful. He or she will have trust in self to identify resources needed to develop strategies in resolving issues, thereby facilitating active adaptation processes.

Among the three domains, meaningfulness plays a pivotal role in providing the motivation for an individual to engage in the search for understanding and resources within one's contexts. Thus, it can strengthen other components on comprehensibility and manageability. Having to see meaning in what one understands he or she can do matters. Thus, the second important component is comprehensibility, followed by manageability-perceiving which resources could be mobilised. Accordingly, Antonovsky suggested an unequal weight placed on the three SOC components [20].

\subsubsection{Generalised and Specific Resistance Resources}

Generalised resistance resources refer to any characteristic of a person, group or situation which facilitates effective coping of tension caused by stressors. This characteristic can take in any form of 'physical, bio-chemical, artefactual-material, cognitive, emotional, valuative-attitudinal, interpersonal-relational and macro-sociocultural' traits ([20], p. 103). Examples include immunity, money, knowledge, happiness, optimism, social support and cultural stability. In other words, coping with stressors involves interaction with one's living context, and is related to ecological thinking [21]. Particularly, the scope of GRRs reflected that health is inextricably linked to the community and ecosystem people are situated in, recognising the social or environmental determinants of health which are not within the direct control of the individual [23]. Depending on the context, types of resources needed to meet the demands of stressors can vary. A person with strong SOC has the ability to use available resources to cope with stressors.

According to the salutogenic health theory, interactions with GRRs offer life experiences of consistency, underload overload balance and participation in valued decision-making, all of which contributing to SOC development [20]. Processes of building up an individual's capacity to mobilise resources are more significant than examining the existence of resources [24]. Thus, GRRs are essential ingredients in developing SOC to move one towards the health pole [21].

Compared with GRRs which have a broader range of utility, specific resistance resources (SRRs) are mobilised only in specific situations [20]. SRRs are context bound and they help people to cope with specific stressors in specific circumstances. For example, getting immediate medical attention via ambulance hotline in times of medical emergencies. Not only do GRRs influence the strength of SOC, they enable the mobilisation of SRRs [25]. Despite the distinction of SRRs from GRRs, both types of resources are essential in creating supportive environment for health promotion [25]. The term 'resistance resources', is used in this chapter to refer to both the variants.

Adopting the salutogenic orientation requires a change in how one perceives issues related to health and well-being. Instead of developing solutions to reduce health-related risks, it focuses on how individuals can be encouraged to use resource-based processes to cope with stressors of daily life, thereby generating health. It requires an appreciation and understanding of these stressors and resistance resources, for their interaction brings about repeated life experiences which generate SOC [26]. 


\subsubsection{Sense of Coherence and Resistance Resources Among Older Adults}

To strengthen SOC among older adults, it is imperative to identify and mobilise resistance resources which facilitate health-promoting processes.

In an integrative review by Tan et al. [27], factors which correlated with SOC positively were reported as resistance resources among older community dwellers. These resources included one's immune function, appraisal of situations, coping strategies, self-care abilities, social support and income. Similarly, social resources such as having time with children and grandchildren, and relocation within past 5 years were associated with SOC among older adults [28].

Several studies examined how SOC mediated effects of various resources on health-related outcomes and well-being among older adults. These studies found that resistance resources such as education [29], marriage among men [30], self-efficacy [29, 31], self-esteem [29, 31, 32], lesser chronic conditions [32], cognitive function [30], lesser depressive symptoms [31], social support and family relations [31, 33], engagement in physical exercises and daily activities [30, 31], competence in motor activities such as speed walking and swimming, and having sense of autonomy and identity [31] contributed to enhancing SOC among older adults. Additionally, how older adults perceived leisure and their self-efficacy to perform leisure were reported as significant resources influencing SOC, which mediates effects on attitudes towards retirement [34]. These causality studies supported the salutogenic concept of resistance resources facilitating one's SOC which in turn promoted health [20].

Alternatively, resistance resources could provide life experiences which reinforce SOC over time and this could be illustrated using a longitudinal cross-lag study design. Monma, Takeda, and Okura found engaging in frequent leisure-time physical activities, such as walking outside home and participating in sports of various intensities, had longitudinal cross-lagged and synchronous effects on SOC among Japanese seniors [35].
A qualitative study reported that positive and forward-looking attitudes, social contacts with family and others, being physically and mentally active, conscious of maintaining positive lifestyle and being satisfied with own life were health-promoting characteristics exhibited by other adults with strong SOC [36]. These findings corresponded with the characteristics displayed by older adults with high QoL and stronger SOC [37].

Regardless of the method used to identify resources related to SOC, findings from this brief literature synthesis corroborated with the health assets reported in a recent systematic review [38]. These assets included self-appraised health and life satisfaction, psychological well-being, social networks, engagement in leisure and social activities, education and financial resources. While our literature synthesis focused on resources related to SOC, the systematic review examined factors which positively influenced multidimensional health at old age [38]. This confirmed a strong relationship between SOC and health, suggesting that resources for SOC could be pooled together with health assets for older adults.

Evident from the literature, most SOC research conducted among older community dwellers employed quantitative methods to examine relationships between resources, SOC and health-related outcomes. Through these quantitative studies on SOC, resources were identified. However, it is more valuable to understand how resources could be mobilised for utilisation compared to prior resource identification in enhancing SOC [20]. Moreover, SOC is activated when one encounters stressful situations or events in life, and this cannot be observed from the outside [39]. Qualitative studies can capture this process and understand precisely what SOC is according to its components, comprehensibility, manageability and meaningfulness, and how SOC intervenes in different situations and experiences [39]. However, there were few SOC or salutogenic theory related qualitative studies conducted in older community dwellers $[12,16,36]$. Amongst them, two studies used the salutogenic perspective to explore perceptions of healthy aging $[12,16]$ while the other purposively sampled older adults 
with high SOC to explore their self-care experiences in health management [36]. Although the third study was not directly related to healthy aging, perspectives of older adults with strong SOC were of key interest to the authors.

All three studies concurred that older adults who were satisfied with their health had positive attitudes and adopted an asset-based perspective. Healthy aging was described in the context of everyday life and interaction with environment, making references to one's physical and mental functions, relationships with people, places and institutions $[12,16,36]$. These findings suggested that salutary factors contributing to healthy aging are embedded in daily life activities of older adults; and these salutary factors involves the mobilisation of one's attitudinal, physical, social and infrastructural resources.

Upon analysis of how the SOC concept was construed, only one of the three qualitative studies reported findings that correspond with the meaningfulness component [16]. This study described health as the ability to engage in meaningful activities but made no reference to comprehensibility and manageability. None of these three studies shed light on the function and application of SOC and its components, which was crucial in understanding SOC-enhancing processes among older adults to advance healthy aging. In relation to resource mobilisation, Naaldenberg et al. [12] revealed challenges encountered by older adults, such as misinterpreted information about resources and negative self-perceived ability to use resources. Such findings on how older adults cope with existing resources are important in identifying problems faced, so that strategies could be undertaken to increase the ease of resource utilisation. The other two qualitative studies merely described health-promoting actions, along with the mention of resources $[16,36]$.

As such, the authors conducted a qualitative study employing the salutogenic perspective to explore the application of SOC concept [40] and mobilisation of resistance resources [41] among older community dwellers to obtain insights on how healthy aging could be promoted. The key findings from this study were thus applied in the development of the SHAPE intervention as described later in this chapter.

\subsubsection{Interventions Enhancing SOC}

Despite empirical evidence calling out to strengthen SOC, there are no clear directives in formulating SOC-enhancing interventions. Based on theoretical explanations, Super et al. [42] proposed that SOC can be strengthened by two processes, namely empowerment and reflection. Empowerment, which acts on the behavioural mechanism, can be facilitated by enabling individuals to identify appropriate resources to manage or avoid stressful situations. Reflection involves the perceptual mechanism to enhance individuals' perceived understanding towards situation, perceived knowledge on resources for mobilisation and perceived feeling that addressing the situation is a meaningful process.

Nonetheless, a good way to uncover SOC strengthening strategies is to learn from existing interventions that used SOC as a dependent variable, regardless whether SOC was enhanced, maintained or weakened [39]. Since the targeted population is older adults, interventions conducted in older populations would first be examined, followed by other pertinent interventions which demonstrated effectiveness in SOC enhancement in other populations.

A total of nine interventional studies which evaluated SOC as an outcome variable among older adults were reviewed in this section to understand the potential SOC-enhancing strategies among older populations. These nine studies were identified based on a comprehensive search on PubMed and CINAHL databases using the keywords 'elderly', 'experimental studies' and 'sense of coherence.' While five studies evaluated on health education interventions related to self-management [43-47], three studies focused on exercise training interventions [48-50] and one study evaluated an intergenerational program involving older adults to read picture books to children [51]. Among the five health education interventions, four of them yielded promising findings in enhancing SOC of older adults 
[43-45, 47]. The three exercise training interventions differed in the duration of intervention, ranging from 12 [50], 24 [48] and 36 weeks [49]. Significant positive SOC change was reported for the 36-week resistance training intervention only [49]. As for the intervention on intergenerational program, only the meaningfulness component increased significantly for older adults whom read picture books to children [51].

Drawing attention to the health education interventions, the authors identified two common characteristics of the four interventions which yielded significant post-test SOC improvements [43-45, 47]. These two characteristics might shed some light on SOC-enhancing strategies. Firstly, these four health education interventions involved active engagement of older adults to be aware of own abilities, resources and health situations. Such intervention engagement was delivered in the form of interactive group activities [47], individual face-to-face interviews using assessment forms $[44,45]$ or senior meeting discussions and a home visit [43]. Secondly, these four interventions equipped and empowered older adults with knowledge on coping strategies of various aspects, ranging from managing daily living needs, aging-related issues, home safety and healthy lifestyle behaviours. Three out of four of these health education interventions even provided educational booklets related to these specific topics [43-45]. On side note, the only health education interventional study which reported decreased SOC scores in both intervention and control groups might have minimal faceto-face active engagement to allow for the deep learning of resources and sharing of knowledge on coping strategies [46]. After all, this health education intervention comprised five motivational interviewing self-care telephone talks with health care professionals.

Among the nine reviewed intervention studies, it is noteworthy that Tan et al. [47] used the salutogenic theory as underpinning theoretical framework for a self-care health education program, titled Resource Enhancement and Activation Program (REAP). This self-care program consisted of 24 group activities conducted twice a week, over 12 weeks. The activities focused on topics related to physical well-being, psychosocial well-being, physical activity and motivation; that is, to motivate older adults in using their internal and external resources. REAP addressed resistance resources in their daily activities in hope to enhance comprehensibility, manageability and meaningfulness of SOC, as reported in their study protocol [52]. Participants whom received the REAP program reported enhanced SOC, particularly in the comprehensibility and manageability domains [47].

Apart from examining SOC-enhancing interventions among older adults, other pertinent SOC-enhancing intervention studies conducted in other populations were considered. Notably, the first intervention designed to strengthen SOC was conducted for patients with mental health illnesses [53]. This 19-week talk therapy intervention consisted of 1.5 -h weekly group meetings involving 5-9 participants and 1 mental health professional. During which, participants discussed about challenges important to them in relevance to their everyday life, followed by reflective conversations on specific topics which they had prepared as homework. The intervention program was guided by five salutogenic therapy principles and its detailed theoretical application was reported [54]. The five salutogenic principles which were adopted are as follows: (a) the health continuum model, (b) the story of the person, (c) health-promoting (salutary) factors, (d) the understanding of tension and strain as potentially health promoting and (e) active adaptation. Significant improvements in total SOC, comprehensibility and manageability were observed with the talk therapy intervention [53].

Based on the review of the nine interventional studies which evaluated SOC as an outcome variable among older adults as well as the salutogenic talk therapy intervention study conducted on mental health patients, the following are possible SOC strengthening approaches, complementing underlying processes on empowerment and reflection [42]. Firstly, these SOC-enhancing interventions included face-to-face social interaction with peers and/or health care professionals to facilitate discussion and mutual learning. Through them, active participation of 'being 
present with others' allowed interactive information exchange and reflective awareness of own situation. Secondly, topics discussed were related to managing everyday life affairs and challenges, regardless of the intervention agenda [43-45, 47, 54]. They developed mastery in perceptual understanding towards demands of everyday life and learning the know-how on how to go about with valued coping activities. After all, SOC is about one's global orientation towards life. Thirdly, the interventions are resource programs that provided participants with information beyond health knowledge and resources, they included concrete skills. They focused on devising solutions through problem-solving or learning to be resourceful in managing challenges encountered. Through them, participants are empowered with resources through knowledge acquisition, clarification, experimentation and reflective awareness of own situation and values.

\subsubsection{The SHAPE Intervention: A Health Resource Program for Senior-Only Household Dwellers Living in a Resource- Rich Environment}

Globally, two in five older adults live independently, either living alone or with spouse only [55]. Owning to changes in marital preferences [56], personal living arrangement preferences [57-59], forced familial circumstances [59] or greater affluence and financial independence among older adults [58], Singapore observed a rise in the number of senior-only households in the recent decade [60]. Where aged care is concerned, familism play an important role in supporting and caring for older adults in Singapore. With lesser familial contact time and exchanges, senior-only household dwellers might receive lesser familial resources that are instrumental to healthy aging in their everyday lives.

Based on the qualitative study the authors conducted on older adults residing in senioronly households in Singapore [41], family members are nevertheless amongst the wealth of health assets they utilised to promote and maintain their health. Apart from residing in a resource-rich external environment where the local government recently channelled considerable capital and support to create an age-friendly living city [61], older adults accrued an internal rich source of personal strengths, life disposition, experiences, self-care skills and knowledge, as well as social resources comprising family, friends, neighbours and social activities [41]. However, these older adults residing in senioronly households displayed variable levels of resourcefulness in gaining access, maintaining and utilising their health resources; some were less proficient in understanding and mobilising them [41]. Furthermore, most of the older adults aged 65 years and above in Singapore received minimal years of education [62] and might not be information savvy. Construction and integration of useful applicable self-care health information and meaningful utility of the older adults' internal and external health assets via a health resource program is thus needed. As such, SHAPE was initiated and designed for senioronly household dwellers to strengthen SOC, better navigate health resources and facilitate them in applying health resources to their own context of health and daily living.

The SHAPE intervention is an integrative multidimensional health resource program with the aim of increasing SOC of senior-only household dwellers. SHAPE focuses on identifying, equipping and strengthening the seniors' existing internal and external resistance resources to adopt health-promoting strategies and cope with aging-related challenges, thereby living a healthy and meaningful life.

The SHAPE-program consisted of 12 weekly group sessions, at least two home visits and a supplementary health resource book. Its curriculum was designed to address the stressors of healthy aging faced by senior-only household dwellers using their health assets/resistance resources [41]. Its content was drawn from the aging experiences of older adults residing in senior-only households to align health-promoting strategies, thereby meeting the demands and needs of their everyday lives. Stressors of healthy aging include physiological decline, shrinking social connec- 
tions, requiring situational tangible assistance, encountering unpredictable life events and pathogenic health orientation [40].

Instead of being teachers who impart health knowledge and coping strategies, health care professionals leading both the group sessions and home visits are resource facilitators. These health care professionals play a critical role in engaging participants in exploration, knowledge acquisition and reflection. Additionally, the principles of salutogenesis have to be integral to the values and beliefs of these resource facilitators to influence and elicit participants' perceptual awareness towards their worldviews, late life and resources at their disposal.

An intervention manual was developed to provide resource facilitators with clear directives on the implementation of the SHAPE intervention. This manual described the principles of SHAPE intervention, and the detailed conduct of each session; all of which were developed to be consistent with the intervention aim and the salutogenic theory. Outline of each session consisted of specific learning objectives and evaluative outcomes, experiential activities arranged in developmental order and process questions in the form of weekly homework for participants to reflect and connect the content of each session to their lives [63]. The supplementary resource book was designed as a consolidative easy-toread health information book that complements the content of the group sessions and home visits. Both the intervention manual and the resource book were content validated by a panel of experts and potential users of the program to ensure the appropriateness, comprehensibility and applicability of the SHAPE intervention. The panel comprised two academic experts in salutogenesis, an academic expert in gerontological social work, one senior physician with geriatrics specialty, one senior nurse trained in geriatrics and gerontology and two senior community social workers. They provided ratings using scoring rubrics and gave comments related to the relevancy, comprehensibility, adequacy and organisation of intervention. Revisions were made by the authors in accordance to the feedback received.

\subsubsection{Application of the Salutogenic Theory in SHAPE Intervention}

The following sections describe and illustrate examples on how the SHAPE intervention approach, content and activities addressed SOC, resistance resources and the salutogenic orientation sequentially. While the authors attempted to delineate the application of the salutogenic theory, the following section contains some overlapping operation of principles and concepts across the aspects on SOC, resistance resources and the salutogenic orientation.

\subsubsection{Sense of Coherence (SOC)}

SOC is a global orientation of how one views the world and individual's stress-rich environment as comprehensible, perceives one's capacity to activate resource utilisation generating healthpromoting strategies as manageable, and view the confrontation with stressors as meaningful, with purpose and worth. Having a better understanding of older adults' stressors, health assets and health-promoting strategies provided the contextual knowledge on SOC strengthening processes $[40,41]$. Comprehensibility can be strengthened by reducing the unpredictability and incomprehension of aging-related processes and daily living challenges. Manageability can be enhanced by supporting and empowering older adults in using their health assets/resistance resources to adopt health-promoting strategies to deal with or avoid the stressor(s). Lastly, meaningfulness can be fortified by activating older adults to reflect and make sense of old age experiences. Having to contemplate about what life at old age meant gives one a better sense of identity and affirmation of own values and life direction [64].

The curriculum of SHAPE intervention is guided by the three SOC components and strengthening processes to equip older adults with resource information to cope with healthy aging stressors. Figure 23.1 illustrates the categorisation of intervention curriculum according to the three SOC components. They are (1) the cognitive aspect of understanding health and aging-related topics, (2) the behavioural aspect of managing health by adopting health-promoting 


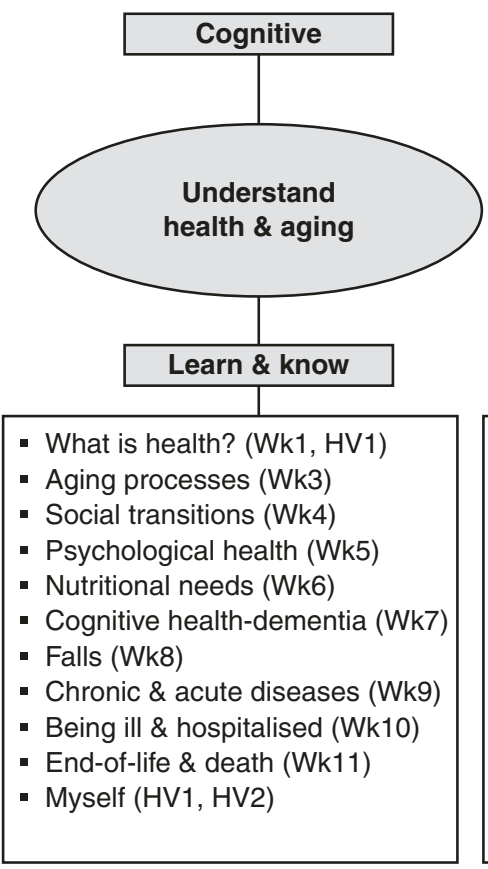

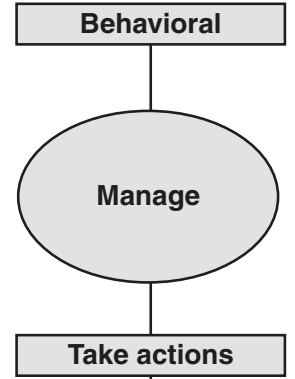

- Keep myself mobile \& active* (regular exercise \& activity)

- Eat nutritious \& healthy food*

- Self-manage chronic diseases*

- Keep a positive psychosocial state of health* (cognitive, social, emotional, spiritual wellness \& sleep)

- Living at home safely* (fall prevention, self-monitoring)

- Manage money \& assets*

- Plan ahead for illness \& death*

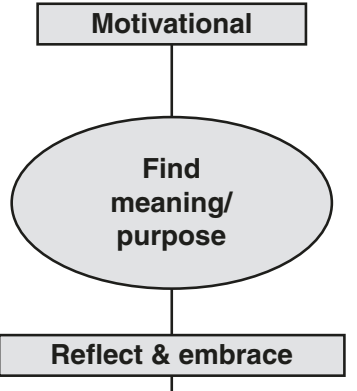

- Appreciate value of being old (Wk 1, 2)

- Live a meaningful \& healthy life (HV1, Wk 2)

- Set goals to achieve better health (HV2)

- Look forward and move on, so that I can be better (Wk 12)

Fig. 23.1 Curriculum of SHAPE intervention categorised according to SOC components. Wk week, $H V$ home visit, *chapters in resource book

actions and (3) the motivational aspects of finding meaning and self-worth at old age.

The understanding of health and aging acts on cognition to increase comprehension and predictability towards health changes and life events encountered, making life in old age structured and consistent. The 12 weekly group sessions encompass a broad range of health and aging topics, which allow participants to be aware of, and gain understanding towards their physical, psychological, social and spiritual experiences during old age.

Provision and facilitation of awareness towards resource information and experiential mobilisation of resources seek to improve perceived ability to manage stressors through behavioural change. During the group sessions, participants and resource facilitators share with each other coping strategies and practice some of these strategies together to tackle aging-related stressors and daily living challenges. Additional resource information is also provided in the SHAPE resource book, which recommends various health-promoting actions and includes information on available resources supporting these actions.

Through personal reflection of experiences in life, one can find meaning, value and purpose, providing the motivation to embrace life in old age. The group sessions in week 1, 2 and 12, as well as the home visits allow participants to look back at their past life experiences, connect to their present and project into the future on how they can live a meaningful healthy late life. These reflective sessions help to seek meaning of one's existence from the past to derive meaning for the present and basis for meaning in future [65, 66]. The sessions also create a sense of awareness, identity and a destination or purpose in life for the participant [67]. These reflections bring coherence of story to one's life, contributing to the cognitive, emotional and motivational aspect of SOC [68].

\subsubsection{Resistance Resources}

Both SOC and resistance resources have a dynamic and reciprocal interactional relationship. While resistance resources contribute to SOC- 
enhancing experiences, SOC contribute to mobilisation of resistance resources to cope with life stressors [69]. To address the three SOC aspects from the perspective of resistance resource mobilisation, the SHAPE intervention promotes the exploration and awareness (cognitive), identification and utilisation (behavioural), and reflection and internalisation of resources to generate SOC-enhancing experiences (motivational) [41]. More specifically, resistance resources create experiences of consistency, load balance, participation in valued decision-making, thereby contributing to comprehensibility, manageability, meaningfulness, respectively [69]. The ecomap of aging assets emerged from the qualitative study provided a visual framework to guide resistance resource mobilisation [41].

Firstly, to create experiences of consistency via SOC comprehensibility, older adults need to process cognitively that there is order and structure in their life. The resource facilitator engages older adults to be aware, apprehend and distinguish the types of appropriate resources to cope with the specific demands of aging-related processes and vulnerabilities during late life.

Secondly, to create experiences of load balance via SOC manageability, older adults need to take on behavioural actions in identifying and utilising the resources available to them. Such experimentation and experiential learning in developing the ability to activate the appropriate resource from their environment allow them to develop the know-how knowledge in initiating and maintaining the utility of the resource. This brings about the adoption of health-promoting actions in their everyday lives. The resource facilitator influences older adults by encouraging, reinforcing and complimenting them for their acts of resource utility.

Lastly, to create experiences of participation in valued decision-making via SOC meaningfulness, older adults' motivation of utilising the specific resources to perform the health-promoting behaviour needs to be intrinsic and based on personal decision-making to shape their health outcomes. Each older adult has to engage him/herself emotionally in making sense of the intended purpose of using the specific resource. During the group sessions and home visits, the resource facilitator probes and prompts older adults to reflect and internalise the insights and meanings drawn from their significant life experiences.

In addition to the significant roles of the resource facilitator, the resource book provides older adults with opportunities to create SOCenhancing experiences independently. The resource book is designed to make one-stop 'resistance resource' information available and accessible to older adults who are less literate or savvy in information technology. Although the titles of the resource book chapters were targeted at SOC manageability (Fig. 23.1), the contents in the chapters addressed both SOC comprehensibility and manageability. To facilitate adoption of health-promoting strategies more easily via the mobilisation of 'resistance resources', the resource book provides contextual information on the local services, communal activities, and government schemes, as well as practical information on where and how these 'resistance resources' can be accessed. At the end of chapter, additional information sources such as hyperlinks and QR codes are provided to allow interested older adults to explore further. The intent of providing such access information was to impel older adults to search for information when needed, as part of a health-promoting strategy in face of stressors.

\subsubsection{The Salutogenic Orientation: Five Salutogenic Principles}

To reinforce the salutogenic orientation and support the operationalisation of SOC and resistance resources, the aforementioned five salutogenic principles (Sect. 23.3.3) which guided the salutogenic therapy talk intervention [54] were also employed in the development of SHAPE intervention. The following describes the five salutogenic principles and illustrates how these principles were integrated in the approach, contents and activities of the SHAPE intervention.

\section{Health as a Continuum}

This salutogenic principle focuses on facilitating older adults to move forward along the health continuum, by addressing health-promoting fac- 
tors instead of managing risk factors to avoid diseases. This requires a perceptual change among older adults if they adopt a disease-oriented definition towards health. The adoption of strengthbased perspective which focuses on what works well can address this. It shifts frame of reference to redefine issues according to experiences of an individual instead of problems or health deficits [70]. Such perspective views older adults 'by their values, strengths, hopes, aspirations, and capacities, regardless of the stressful or burdensome nature of the situation around them' (p. 642-43). With an assumption that people are capable of growth and change, older adults can be assisted to develop insight to their strengths and resources [71].

To embrace the strengths-based perspective, approaches used in various strength-based models, such as appreciative inquiry, building capacities and solution-focused therapy [70], were incorporated in SHAPE intervention.

Appreciative inquiry uses a way of asking questions to appreciate ideas that have worked and use these ideas to envision and shape the future [72]. The resource facilitator can engage older adults in 'strengths chats' by asking the right questions [70]. Asking about past positive experiences can uncover and draw on individual's strengths while inquiring about the form of support needed to build upon existing strengths, and information about past and present issues influencing or preventing the use of strengths could help in formulating health-promoting strategies [70, 73]. Using the same question in the qualitative interview [40], older adults can be asked to share their healthiest or most energised moments during their late life to elucidate characteristics which create health in them. They could be guided to perceive that these moments of accomplishment on desired pursuits or activities are examples of moving forward along the health continuum. In this way, reframing and redefinition of health from pathogenic to salutogenic perspective is facilitated among the older adults [40]. This also expands their meaning of being healthy.

Scale questions, a solution-focused therapy technique which use scale from 0 to 10 , can be used as a tool to simulate and facilitate movement on the health continuum [74]. In the SHAPE intervention, the following question is used: 'On a scale of 0 to 10 , where 0 refers to worst imaginable life and 10 as best imaginable life, how would you rate yourself as living meaningfully and healthily now?'. If the older adult rates four, the resource facilitator can ask why the rating is not a two or six to find out possibilities of what the former hopes to achieve and what had been achieved. It allows exploration of possible progress of the older adult's health position in the immediate future [75].

\section{The Story of a Person}

Having to learn about the story of an older adult recognises him or her as a person with rich diverse experiences, mould by a set of attitudes, beliefs, values, social cultural norms, daily life activities and interaction with their physical, social and structural environment. It is contextualised and sees a person behind the illness and disease [20], akin to person-centred thinking in contrast to disease-centeredness or the focus on impairment in care delivery [76].

Underpinned by values of respect for person, individual's right to self-determination, mutual understanding and respect [77], person-centred approach traced back to humanistic psychology and person-centred therapy [78]. Elements of person-centred approach involves perceiving a person holistically and as an unique individual, being empathetic towards his/her experiences, needs, values and preferences, having mutual trust and relationship with each other and participative decision-making through information exchange and communication [79-82], with the goal of achieving a meaningful life [79]. It requires openness to experiences, being curious, understanding, having respect and the establishment of trusting, collaborative and egalitarian relationship between older adults and the resource facilitator.

In SHAPE intervention, part of understanding the story of person for the resource facilitator is to use narrative accounts as a tool to understand participants' values in life [80]. Narrative accounts also emanate participants' awareness towards own 
living situation, facilitating conscious recognition of own internal and external resources to cope with it. This tool uses language expression to organise one's thoughts and feelings, creating and describing a 'pre-understanding' of situations [83]. It is insight-oriented because it sheds light on the participant's coping capacity and strategies to adopt [54].

\section{Health-Promoting Factors}

Contrary to deficit orientation, salutogenic thinking focuses on health-promoting factors through resource mobilisation, building and enhancing capacities through process of empowerment [21]. It has been suggested that salutogenesis could provide the underpinning theoretical basis for health assets [84, 85].

The SHAPE intervention adopts an asset-based approach to facilitate aging assets mobilisation. Apart from providing information needed for resource mobilisation, SHAPE encourages older adults to gain insight that they can contribute to their own health by identifying and learning how to access and use resources [86]. The resource facilitator engages older adults to recognise their personal, social, economic and environmental factors as health assets which they could use to pursue desired activities or health goals [38].

In the intervention, simple activities are planned to raise older adults' awareness towards their resources. This includes reflection on identifying their unique strengths/attributes and plotting daily activity routine on a 24 -h activity clock to identify activity participation preferences and involvement. Also, having older adults to draw their own social eco-map allows them to have an overview of their existing social capital and reflect on how some of these relationships could be strengthen or improved. Unlike in social work profession, social eco-map is used as an assessment tool to understand client's sources of psychosocial stress and transactional relationships, aiding in development of care interventions such as discharge planning [87]. During the intervention, participants are encouraged to build their social network by establishing and maintaining new social relationships, such as making friends. To further equip older adults with selfcare knowledge and relevant external resources such as community services and government support schemes, exchange of information through printed materials and discussions are facilitated. This involves the resource facilitator to share relevant health knowledge and resource information with older adults too.

\section{Stress and Strain as Potentially Health Promoting}

According to Antonovsky, stressors and tension create life experiences of inconsistency, overload and lack of engagement in decision-making, which provide situations for developing coping capacity and generating SOC [20]. Being challenged by tension-causing stressors to adapt is salutary and health promoting.

Confrontation as a form of coping strategy to stressors has been found to have mediating effects on both SOC and self-care behaviours [88]. Having to confront and discuss openly about stressors could reduce older adults' incomprehension, enhance manageability and promote acceptance towards it. This can result older adults in resource activation and adopting positive health behaviours.

In SHAPE intervention, stressors such as unpredictable illness and death are confronted by anticipating experiences of and preparing for illness and death. Examples of activities include hands-on usage of assistive ambulatory aids, exposure to common medical requisites encountered during hospitalisation and introducing advance care plans [52]. Although this approach presents an adverse portrayal to older adults, it can be introduced in a safe learning environment for them to inquire and clarify doubts.

As stressors are omnipresent [20], it is important to universalise feelings of tension by acknowledging normalcy of stressful experiences [54]. This requires the older adults to acknowledge and accept stressors such as physiological and social changes of aging, and times of vulnerability requiring tangible assistance. Having to discuss and hear stories of others who underwent similar experiences help in normalising these feelings of tension. Also, such perception towards stress and tension should be consistently demonstrated in the resource facilitator's attitude and interaction with older adults during the SHAPE intervention [54]. 


\section{Active Adaptation}

Aforementioned, salutogenic processes which involve developing personal capacity for resourcefulness are more important than providing resources as pre-requisites for SOC enhancement $[20,24]$. Creating such experiences during SHAPE intervention would allow resources to be internalised by older adults through personal usage, giving them a sense of ownership and control of their own health and aging journey [24]. Activities such as hands-on preparation of nutritious meal, acts of physical exercises and accomplishment of personal health goals using 'resistance resources' could provide experiential and adaptation opportunities for the older adults.

In addition, as one ages and confronts with life experiences, personal meaning to life and health changes [64]. The use of self-reflection is an essential tool to construct participants' personal meaning of health and meaning in life at old age. It creates self-awareness of knowing own self, contributing to meaning-focused health-promoting strategies as part of adaptation. This, however, is a developmental process which requires creation and self-discovery [68]. The use of narrative life stories can contribute to older adults' sense of self, uncover their meaning in life, allow them to accept life, and live with purpose and enthusiasm [64]. A quick life review activity using a life ruler can allow older adults to reminisce and appreciate past experiences of personal development, achievements, loss and hardship in their life journey. It facilitates participants to examine how their stories contribute to their meaning in life, and come to terms with aging [65]. Integrating experiences of past difficult transitions and vulnerabilities help them to accept loss and hardship, preserve their selfworth and adapt to present life stressors [89].

\subsection{Conclusion}

Salutogenesis introduces a paradigm on the origins of health; what is health and how health can be created. In the context of healthy aging, the salutogenic perspective recognises aging as a positive developmental process of a person and values the life experiences of the person. This perspective involves a conscious reflection of how an individual views life as a whole to cope with the salutary vulnerabilities and stressors in old age. Healthy aging is a multidimensional concept embraced in the SHAPE intervention. Based on the salutogenic principles, SOC and resistance resources, SHAPE is a health resource program that employs an asset-based, person-centric and insight-oriented approach. Apart from the intervention approach, content and activities, the SHAPE intervention places emphasis on the significant role of health professionals conducting the intervention to communicate and elicit the salutogenic perspective to its target audience-senior-only household dwellers. To advance this salutogenic initiative, the SHAPE intervention needs to be piloted to test for its feasibility.

\section{Take Home Messages}

- The salutogenic perspective on healthy aging views aging as an achievement; where older people are valued as assets for their wealth of experiences, resources, skills and knowledge.

- The SHAPE intervention embraces the multidimensional concept of healthy aging; It covers a range of comprehensive health and aging topics encompassing physical, psychological, psychological, social and spiritual aspects of aging.

- The concepts on sense of coherence, resistance resources and the salutogenic orientation are operationalised and illustrated in the intervention approach, curriculum and the conduct of SHAPE.

- As a health resource program, the SHAPE intervention aims to strengthen 'resistance resources' of older adults, so as to promote the adoption of health-promoting strategies and coping of stressors at old age; it employs an asset-based, person-centric and insightoriented approach.

- Health professionals conducting salutogenic theory based interventions such as SHAPE play an important role of communicating and eliciting the salutogenic perspective to the participants. 
Acknowledgements This research project was funded by Singapore Ministry of Education Social Science Research Thematic Grant. Any opinions, findings, and conclusions or recommendations expressed in this material are those of the author(s) and do not reflect the views of the Singapore Ministry of Education or the Singapore Government.'

\section{References}

1. Rowe JW, Kahn RL. Human aging: usual and successful. Science. 1987;237(4811):143-9. https://doi. org/10.1126/science.3299702.

2. Niccoli T, Partridge L. Ageing as a risk factor for disease. Curr Biol. 2012;22(17):R741-52. https://doi. org/10.1016/j.cub.2012.07.024.

3. Ng TP, Feng L, Nyunt MS, Larbi A, Yap KB. Frailty in older persons: multisystem risk factors and the frailty risk index (FRI). J Am Med Dir Assoc. 2014;15(9):635-42. https://doi.org/10.1016/j.jamda. 2014.03.008

4. Niederstrasser NG, Rogers NT, Bandelow S. Determinants of frailty development and progression using a multidimensional frailty index: evidence from the English Longitudinal Study of Ageing. PLoS One. 2019;14(10):e0223799. https://doi.org/10.1371/ journal.pone.0223799.

5. Duplaga M, Grysztar M, Rodzinka M, Kopec A. Scoping review of health promotion and disease prevention interventions addressed to elderly people. BMC Health Serv Res. 2016;16(Suppl 5):278. https:// doi.org/10.1186/s12913-016-1521-4.

6. United Nations. Political declarations and Madrid International Plan of Action on Ageing. New York: United Nation; 2002.

7. Bacsu J, Jeffery B, Abonyi S, Johnson S, Novik N, Martz D, et al. Healthy aging in place: perceptions of rural older adults. Educ Gerontol. 2013;40(5):32737. https://doi.org/10.1080/03601277.2013.802191.

8. Waldbrook N. Exploring opportunities for healthy aging among older persons with a history of homelessness in Toronto. Can Soc Sci Med. 2015;128:12633. https://doi.org/10.1016/j.socscimed.2015.01.015.

9. Sixsmith J, Sixsmith A, Fange AM, Naumann D, Kucsera C, Tomsone S, et al. Healthy ageing and home: the perspectives of very old people in five European countries. Soc Sci Med. 2014;106:1-9. https://doi.org/10.1016/j.socscimed.2014.01.006.

10. Lee LY, Fan RY. An exploratory study on the perceptions of healthy ageing among Chinese adults in Hong Kong. J Clin Nurs. 2008;17(10):1392-4. https://doi. org/10.1111/j.1365-2702.2007.02273.x.

11. Tohit N, Browning CJ, Radermacher H. 'We want a peaceful life here and hereafter': healthy ageing perspectives of older Malays in Malaysia. Ageing Soc. 2011;32(3):405-24. https://doi.org/10.1017/ s0144686x11000316.
12. Naaldenberg J, Vaandrager L, Koelen M, Leeuwis C. Aging populations' everyday life perspectives on healthy aging: new insights for policy and strategies at the local level. J Appl Gerontol. 2011;31(6):711-33. https://doi.org/10.1177/0733464810397703.

13. Stephens C, Breheny M, Mansvelt J. Healthy ageing from the perspective of older people: a capability approach to resilience. Psychol Health. 2015;30(6):715-31. https://doi.org/10.1080/0887044 6.2014.904862.

14. Manasatchakun P, Chotiga P, Roxberg A, Asp M. Healthy ageing in Isan-Thai culture--a phenomenographic study based on older persons' lived experiences. Int J Qual Stud Health Well Being. 2016;11:29463. https://doi.org/10.3402/qhw.v11.29463.

15. Thanakwang K, Soonthorndhada K, Mongkolprasoet J. Perspectives on healthy aging among Thai elderly: a qualitative study. Nurs Health Sci. 2012;14(4):472-9. https://doi.org/10.1111/j.1442-2018.2012.00718.x.

16. Bryant LL, Corbett KK, Kutner JS. In their own words: a model of healthy aging. Soc Sci Med. 2001;53(7):927-41. https://doi.org/10.1016/S02779536(00)00392-0.

17. Nguyen H, Lee JA, Sorkin DH, Gibbs L. "Living happily despite having an illness": perceptions of healthy aging among Korean American, Vietnamese American, and Latino older adults. Appl Nurs Res. 2019;48:30-6. https://doi.org/10.1016/j.apnr. 2019.04.002.

18. Waites C. Examining the perceptions, preferences, and practices that influence healthy aging for African American older adults: an ecological perspective. J Appl Gerontol. 2013;32(7):855-75. https://doi. org/10.1177/0733464812446020.

19. Waites CE, Onolemhemhen DN. Perceptions of healthy aging among African-American and Ethiopian elders. Ageing Int. 2014;39(4):369-84.

20. Antonovsky A. Unraveling the mystery of health: how people manage stress and stay well. 1st ed. San Francisco: Jossey-Bass; 1987.

21. Lindstrom B, Eriksson M. The Hitchhiker's guide to salutogenesis. Salutogenic pathways to health promotion. Folhalsan Research Centre: Helsinki; 2010.

22. Mittelmark MB, Bull T. The salutogenic model of health in health promotion research. Glob Health Promot. 2013;20(2):30-8. https://doi.org/10.1177/ 1757975913486684.

23. Harris N, Grootjans J. The application of ecological thinking to better understand the needs of communities of older people. Australas J Ageing. 2012;31(1):17-21. https://doi.org/10.1111/j.1741-6612.2010.00501.x.

24. Cowley S, Billings JR. Resources revisited: salutogenesis from a lay perspective. J Adv Nurs. 1999;29(4):994-1004. https://doi.org/10.1046/j.13652648.1999.00968.x.

25. Mittelmark MB, Bull T, Daniel M, Urke H. Specific resistance resources in the salutogenic model of health. In: Mittelmark MB, Sagy S, Eriksson M, Bauer GF, Pelikan JM, Lindstrom B, et al., editors. 
The handbook of salutogenesis. Cham: Springer; 2017. p. 71-6.

26. Antonovsky A. The salutogenic model as a theory to guide health promotion. Health Promot Int. 1996;11(1):11-8. https://doi.org/10.1093/heapro/ 11.1.11.

27. Tan KK, Vehvilainen-Julkunen K, Chan SW. Integrative review: salutogenesis and health in older people over 65 years old. J Adv Nurs. 2014;70(3):497-510. https://doi.org/10.1111/jan. 12221.

28. Mellqvist M, Wiktorsson S, Joas E, Ostling S, Skoog I, Waern M. Sense of coherence in elderly suicide attempters: the impact of social and health-related factors. Int Psychogeriatr. 2011;23(6):986-93. https:// doi.org/10.1017/S1041610211000196.

29. Wiesmann U, Hannich H-J. A salutogenic view on subjective Well-being in active elderly persons. Aging Ment Health. 2008;12(1):56-65. https://doi. org/10.1080/13607860701365998.

30. Read S, Aunola K, Feldt T, Leinonen R, Ruoppila I. The relationship between generalized resistance resources, sense of coherence, and health among Finnish people aged 65-69. Eur Psychol. 2005;10(3):244-53. https:// doi.org/10.1027/1016-9040.10.3.244.

31. Wiesmann U, Hannich H-J. A salutogenic analysis of healthy aging in active elderly persons. Res Aging. 2010;32(3):349-71. https://doi.org/10.1177/ 0164027509356954.

32. Wiesmann U, Hannich H-J. The contribution of resistance resources and sense of coherence to life satisfaction in older age. J Happiness Stud. 2013;14(3):911-28. https://doi.org/10.1007/s10902012-9361-3.

33. Chiang HH, Lee TS. Family relations, sense of coherence, happiness and perceived health in retired Taiwanese: analysis of a conceptual model. Geriatr Gerontol Int. 2018;18(1):154-60. https://doi. org/10.1111/ggi.13141.

34. Lee C, Payne LL, Berdychevsky L. The roles of leisure attitudes and self-efficacy on attitudes toward retirement among retirees: a sense of coherence theory approach. Leis Sci. 2020;42(2):152-69. https:// doi.org/10.1080/01490400.2018.1448025.

35. Monma T, Takeda F, Okura T. Physical activities impact sense of coherence among community-dwelling older adults. Geriatr Gerontol Int. 2017;17(11):2208-15. https://doi.org/10.1111/ggi.13063.

36. Söderhamn U, Dale B, Söderhamn O. Narrated lived experiences of self-care and health among ruralliving older persons with a strong sense of coherence. Psychol Res Behav Manag. 2011;4:151-8. https://doi. org/10.2147/PRBM.S27228.

37. Borglin G, Jakobsson U, Edberg AK, Hallberg IR. Older people in Sweden with various degrees of present quality of life: their health, social support, everyday activities and sense of coherence. Health Soc Care Community. 2006;14(2):136-46. https:// doi.org/10.1111/j.1365-2524.2006.00603.x.
38. Hornby-Turner YC, Peel NM, Hubbard RE. Health assets in older age: a systematic review. BMJ Open. 2017;7(5):e013226. https://doi.org/10.1136/ bmjopen-2016-013226.

39. Yamazaki Y, Togari T, Sakano J. Toward development of intervention methods for strengthening the sense of coherence: suggestions from Japan. In: Muto T, Nakahara T, Nam EW, editors. Asian perspectives and evidence on health promotion and education. Tokyo: Springer Japan; 2011. p. 118-32.

40. Seah B, Espnes GA, Ang ENK, Lim JY, Kowitlawakul Y, Wang W. Achieving healthy ageing through the perspective of sense of coherence among senior-only households: a qualitative study. Aging Ment Health. 2020:1-10. https://doi.org/10.1080/13607863.2020.1 725805 .

41. Seah B, Espnes GA, Ang ENK, Lim JY, Kowitlawakul Y, Wang W. Mobilisation of health assets among older community dwellers residing in senior-only households in Singapore: a qualitative study. BMC Geriatr. 2020;20:411.

42. Super S, Wagemakers MAE, Picavet HSJ, Verkooijen KT, Koelen MA. Strengthening sense of coherence: opportunities for theory building in health promotion. Health Promot Int. 2016;31(4):869-78. https://doi. org/10.1093/heapro/dav071.

43. Arola LA, Barenfeld E, Dahlin-Ivanoff S, HaggblomKronlof G. Distribution and evaluation of sense of coherence among older immigrants before and after a health promotion intervention - results from the RCT study promoting aging migrants' capability. Clin Interv Aging. 2018;13:2317-28. https://doi. org/10.2147/CIA.S177791.

44. Hourzad A, Pouladi S, Ostovar A, Ravanipour M. The effects of an empowering self-management model on self-efficacy and sense of coherence among retired elderly with chronic diseases: a randomized controlled trial. Clin Interv Aging. 2018;13:2215-24. https://doi.org/10.2147/CIA.S183276.

45. Musavinasab M, Ravanipour M, Pouladi S, Motamed $\mathrm{N}$, Barekat M. The effect of self-management empowerment model on the sense of coherence among elderly patients with cardiovascular disease. Educ Gerontol. 2015;42(2):100-8. https://doi.org/10.1080/ 03601277.2015.1078691.

46. Sundsli K, Soderhamn U, Espnes GA, Soderhamn O. Self-care telephone talks as a health-promotion intervention in urban home-living persons $75+$ years of age: a randomized controlled study. Clin Interv Aging. 2014;9:95-103. https://doi.org/10.2147/cia.s55925.

47. Tan KK, Chan SW, Wang W, Vehvilainen-Julkunen K. A salutogenic program to enhance sense of coherence and quality of life for older people in the community: a feasibility randomized controlled trial and process evaluation. Patient Educ Counsel. 2016;99(1):108-16. https://doi.org/10.1016/j.pec. 2015.08.003.

48. Ericson H, Skoog T, Johansson M, Wahlin-Larsson B. Resistance training is linked to heightened posi- 
tive motivational state and lower negative affect among healthy women aged 65-70. J Women Aging. 2018;30(5):366-81. https://doi.org/10.1080/0895284 1.2017.1301720.

49. Kekalainen T, Kokko K, Sipila S, Walker S. Effects of a 9-month resistance training intervention on quality of life, sense of coherence, and depressive symptoms in older adults: randomized controlled trial. Qual Life Res. 2018;27(2):455-65. https://doi.org/10.1007/ s11136-017-1733-z.

50. Pakkala I, Read S, Sipila S, Portegijs E, Kallinen M, Heinonen A, et al. Effects of intensive strength-power training on sense of coherence among 60-85-year-old people with hip fracture: a randomized controlled trial. Aging Clin Exp Res. 2012;24(3):295-9. https:// doi.org/10.1007/BF03325261.

51. Murayama Y, Ohba H, Yasunaga M, Nonaka K, Takeuchi R, Nishi M, et al. The effect of intergenerational programs on the mental health of elderly adults. Aging Ment Health. 2015;19(4):306-14. https://doi. org/10.1080/13607863.2014.933309.

52. Tan KK, Chan SWC, Vehviläinen-Julkunen K. Selfcare program for older community-dwellers: protocol for a randomized controlled trial. Cent Eur J Nurs Midwifery. 2014;5(4):145-55. https://doi. org/10.15452/cejnm.2014.05.0010.

53. Langeland E, Riise T, Hanestad BR, Nortvedt MW, Kristoffersen K, Wahl AK. The effect of salutogenic treatment principles on coping with mental health problems a randomised controlled trial. Patient Educ Couns. 2006;62(2):212-9. https://doi.org/10.1016/j. pec.2005.07.004.

54. Langeland E, Wahl AK, Kristoffersen K, Hanestad BR. Promoting coping: salutogenesis among people with mental health problems. Issues Ment Health Nurs. 2007;28(3):275-95. https://doi.org/10.1080/ 01612840601172627.

55. United Nations. World population aging 2017-highlights. New York: United Nations, Department of Economic and Social Affairs; 2017. Contract No.: ST/ESA/SER.A/397.

56. Chan A, Yap MT. Baby-boomers survey Singapore: National University of Singapore. 2009. www.nas. gov.sg/archivesonline/data/pdfdoc/.../baby_boomer_ survey_7jan09.pdf. Accessed 16 Feb 2019.

57. Soon GY, Tan KK, Wang W, Lopez V. Back to the beginning: perceptions of older Singaporean couples living alone. Nurs Health Sci. 2015;17(3):402-7. https://doi.org/10.1111/nhs.12203.

58. Thang LL. Living independently, living well: seniors living in housing and development Board Studio Apartments in Singapore. Senri Ethnol Stud. 2014;87:59-78.

59. Wong YS, Verbrugge LM. Living alone: elderly Chinese Singaporeans. J Cross Cult Gerontol. 2009;24(3):209-24. https://doi.org/10.1007/s10823008-9081-7.

60. Ministry of Social and Family Development. Families and households in Singapore, 2000-2017. Singapore:
Ministry of Social and Family Development, Strategic Planning, Research and Development Division; 2019.

61. Ministry of Health. In: Health Mo, editor. I feel young in my Singapore: action plan for successful ageing. Singapore: Ministry of Health; 2016.

62. Singapore Department of Statistics. Population trends, 2018. Singapore: Ministry of Trade \& Industry; 2018.

63. Schneider JK, Cook JH Jr. Planning psychoeducational groups for older adults. J Gerontol Nurs. 2005;31(8):33-8. https://doi.org/10.3928/0098-913420050801-12.

64. Moore SL, Metcalf B, Schow E. The quest for meaning in aging. Geriatr Nurs. 2006;27(5):293-9. https:// doi.org/10.1016/j.gerinurse.2006.08.012.

65. Haber D. Life review: implementation, theory, research, and therapy. Int $\mathrm{J}$ Aging Hum Dev. 2006;63(2):153-71. https://doi.org/10.2190/da9grhk5-n9jp-t6cc.

66. Reker G, Wong P. Personal meaning in life and psychosocial adaptation in the later years. In: Wong P, editor. The human quest for meaning: theories, research and applications. 2nd ed. New York: Routledge; 2012. p. 433-56.

67. McAdams D. Meaning and personality. In: Wong $\mathrm{P}$, editor. The human quest for meaning: theories, research and applications. 2nd ed. New York: Routledge; 2012. p. 107-23.

68. Hupkens S, Machielse A, Goumans M, Derkx P. Meaning in life of older persons: an integrative literature review. Nurs Ethics. 2016;25(8):973-91. https://doi.org/10.1177/0969733016680122.

69. Idan O, Eriksson M, Al-Yagon M. The salutogenic model: the role of generalized resistance resources. In: tThe handbook of Salutogenesis [Internet]. Cham: Springer; 2016. https://www.ncbi.nlm.nih.gov/books/ NBK435841/. Accessed 2 Feb 2020.

70. Hirst SP, Lane A, Stares R. Health promotion with older adults experiencing mental health challenges: a literature review of strength-based approaches. Clin Gerontol. 2013;36(4):329-55. https://doi.org/10.1080 /07317115.2013.788118.

71. Saleebey D. Introduction: power in the people. In: Saleebey D, editor. The strengths perspective in social work practice. 5th ed. New York: Pearson; 2009. p. 1-23.

72. Cooperrider DL, Whitney D, Stravros JM. Appreciative inquiry handbook: for leaders of change. 2nd ed. Brunswick: Crown Custom Publishing; 2008.

73. Gottlieb LN, Gottlieb B. Strengths-based nursing: a process for implementing a philosophy into practice. J Fam Nurs. 2017;23(3):319-40. https://doi. org/10.1177/1074840717717731.

74. Ratner H, George E, Iveson C. Solution focused brief therapy. London: Routledge; 2012.

75. Iveson C, George E, Ratner H. Scales. In: Brief coaching: a solution focused approach. London: Routledge; 2012. p. 79-98.

76. Leplege A, Gzil F, Cammelli M, Lefeve C, Pachoud B, Ville I. Person-centredness: concep- 
tual and historical perspectives. Disabil Rehabil. 2007;29(20-21):1555-65. https://doi.org/10.1080/ 09638280701618661.

77. McCormack B, Dulmen AM, Eide H, Skovdahl K, Eide T. Person-centredness in healthcare policy, practice and research. In: Person-centred healthcare research. Hoboken: Wiley; 2017. p. 3-17.

78. Rogers CR. On becoming a person: a therapist's view of psychotherapy. Boston: Houghton Mifflin; 1961.

79. Hakansson Eklund J, Holmstrom IK, Kumlin T, Kaminsky E, Skoglund K, Hoglander J, et al. "Same same or different?" A review of reviews of personcentered and patient-centered care. Patient Educ Couns. 2019;102(1):3-11. https://doi.org/10.1016/j. pec.2018.08.029.

80. McCormack B. A conceptual framework for personcentred practice with older people. Int J Nurs Pract. 2003;9(3):202-9. https://doi.org/10.1046/j.1440172X.2003.00423.x.

81. Thorarinsdottir K, Kristjansson K. Patients' perspectives on person-centred participation in healthcare: a framework analysis. Nurs Ethics. 2014;21(2):129-47. https://doi.org/10.1177/0969733013490593.

82. Wilberforce M, Challis D, Davies L, Kelly MP, Roberts C, Clarkson P. Person-centredness in the community care of older people: a literature-based concept synthesis. Int J Soc Welf. 2017;26(1):86-98. https://doi.org/10.1111/ijsw.12221.

83. Payne M. Chapter two: ideas informing narrative therapy. In: Narrative therapy: an introduction for coun- sellors [Internet]. London: SAGE; 2006. p. 18-36. http://sk.sagepub.com/books/narrative-therapy-2e.

84. Eriksson M, Lindström B. Bringing it all together: the salutogenic response to some of the most pertinent public health dilemmas. In: Morgan A, Davies M, Ziglio E, editors. Health assets in a global context: theory, methods, action. New York: Springer; 2010. p. 339-51.

85. Morgan A, Ziglio E. Revitalising the evidence base for public health: an assets model. Promot Educ. 2007;14(2_Suppl):17-22. https://doi.org/10.1177/10 253823070140020701x.

86. Whiting L, Kendall S, Wills W. An asset-based approach: an alternative health promotion strategy? Community Pract. 2012;85(1):25-8.

87. Miller VJ, Fields NL, Adorno G, Smith-Osborne A. Using the eco-map and ecosystems perspective to guide skilled nursing facility discharge planning. J Gerontol Soc Work. 2017;60(6-7):504-18. https:// doi.org/10.1080/01634372.2017.1324548.

88. Li Z, Liu T, Han J, Li T, Zhu Q, Wang A. Confrontation as a mediator between sense of coherence and selfmanagement behaviors among elderly patients with coronary heart disease in North China. Asian Nurs Res. 2017;11(3):201-6. https://doi.org/10.1016/j. anr.2017.08.003.

89. Stevens-Ratchford RG. Occupational engagement: motivation for older adult participation. Top Geriatr Rehabil. 2005;21(3):171-81.

Open Access This chapter is licensed under the terms of the Creative Commons Attribution 4.0 International License (http://creativecommons.org/licenses/by/4.0/), which permits use, sharing, adaptation, distribution and reproduction in any medium or format, as long as you give appropriate credit to the original author(s) and the source, provide a link to the Creative Commons license and indicate if changes were made.

The images or other third party material in this chapter are included in the chapter's Creative Commons license, unless indicated otherwise in a credit line to the material. If material is not included in the chapter's Creative Commons license and your intended use is not permitted by statutory regulation or exceeds the permitted use, you will need to obtain permission directly from the copyright holder. 